\title{
Point source outbreaks of Campylobacter jejuni infection - are they more common than we think and what might cause them?
}

\author{
THE CAMPYLOBACTER SENTINEL SURVEILLANCE SCHEME \\ COLLABORATORS*
}

(Accepted 7 January 2003)

\section{SUMMARY}

Despite being the commonest bacterial cause of infectious intestinal disease (IID) in England and Wales, outbreaks of campylobacter infection are rarely reported. However, data from the Campylobacter Sentinel Surveillance Scheme suggested that outbreaks might be more common than was previously suspected, since a high proportion of cases reported other illness in the home or in the community at the same time as their illness. To identify factors that might lead to these apparent outbreaks, the exposures of cases of Campylobacter jejuni infection reporting other illness, either in the home or the community, were compared with those for cases not reporting other illness using case-case methodology. Illness in the home was associated with consuming organic meats in the winter, having contact with a pet suffering from diarrhoea or visiting a farm in the 2 weeks before the onset of symptoms. Illness in the community was associated with the consumption of foods in restaurants or drinking unpasteurized milk. Prevention of campylobacter infection requires that better methods of outbreak detection and investigation are developed, which in turn should lead to a better understanding of risk factors.

\section{INTRODUCTION}

Campylobacters are the commonest bacterial cause of infectious intestinal disease (IID) in England and Wales [1]. Laboratory reports of faecal isolates have exceeded 50000 cases annually for the past 5 years [1], and these cases represent a fraction of those cases thought to occur in the community at large [2]. Despite this, outbreaks of campylobacter infection are rarely reported, with only $2 \%$ of all outbreaks of IID reported to the Public Health Laboratory Service (PHLS) Communicable Disease Surveillance Centre (CDSC) between 1992 and 1999 being attributed to this pathogen [3, 4].

Outbreaks of campylobacter infection might go unrecognized for several reasons. Firstly, the long incubation period [5] means that cases might not recall

\footnotetext{
* Author for correspondence: I. A. Gillespie, PHLS Communicable Disease Surveillance Centre, 61 Colindale Avenue, London NW9 5EQ.
}

certain common exposures, or that exposure might have occurred outside the period of enquiry. Secondly, investigators might have insufficient resources to investigate such large numbers of individual cases [6]. Finally, having identified a cluster of cases in space and time, investigators have not, until relatively recently, had a central reference facility to add microbiological typing evidence to epidemiological information, which is often needed in the recognition or confirmation of outbreaks [4].

The epidemiological and microbiological evidence gained from outbreak investigations provides valuable data on the sources and vehicles of infection [7]. The lack of recognized outbreaks means that risk factors for campylobacter infection are not easily identified, and this hampers the identification, implementation and monitoring of intervention strategies.

The Campylobacter Sentinel Surveillance Scheme, which was launched in May 2000, aims to generate new hypotheses for campylobacter infection through 
the integration of standardized epidemiological and microbiological typing data [8]. Data from the first year of the scheme suggested that point source outbreaks of campylobacter infection might be more common than was previously suspected, with a high proportion of cases reporting concurrent illness in the home or in the community $[9,10]$.

The aim of this study was to determine what factors, if any, might lead to these apparent outbreaks, by comparing the exposures of cases reporting other illness, either in the home or the community, with those cases who did not, using case-case methodology [11].

\section{METHODS}

Epidemiological information for all laboratoryconfirmed campylobacter cases in the participating health authorities was collected using a standard, structured questionnaire. Demographic and clinical information was captured, in addition to the patients' travel history and exposures to food, water, the environment and animals in the 2 weeks prior to illness. Completed questionnaires were forwarded to the Public Health Laboratory Service (PHLS) Communicable Disease Surveillance Centre (CDSC) for data entry. Laboratory isolates were referred to the Campylobacter Reference Unit of the PHLS Laboratory of Enteric Pathogens for speciation [12], serotyping [13], phage typing [14] and antimicrobial resistance testing [15].

The epidemiological and typing datasets were combined using the patients' surnames and dates of birth, and analysed using Stata version seven (Stata Corporation, College Station, TX, USA). The date of onset was used to define the season in which illness commenced. 'Spring' was defined as March to May, 'summer' from June to August, 'autumn' from September to November and 'winter' from December to February. Standard occupational classification was employed to determine cases' socio-economic group [16]. Additional categories were created for individuals who described their occupation as unemployed, pre-school child, school child, student, homemaker, retired, part time, and for those who were unable to work due to disabilities or long-term illness. Food exposures were coded to compare those who had eaten a particular food in the 2 weeks prior to onset (once or more than once) with those who had not. Contact with raw meat was coded to compare no contact with $1,2-5,6-10$ and more than 11 times. Daily water consumption was coded to differentiate no exposure from 1 to 4,5 to 9 and 10 or more glasses of water drunk.

Patient age was stratified into 10 -year age groups. Household size was recorded to compare those households with 1-4 (adults or children), with 5-9 and with 10 or more members. Individuals with missing data were omitted from the analyses using those data items.

For the case-case comparison, cases of $C$. jejuni infection who reported individuals with similar symptoms at the same time (either in their home or in the community) were considered 'cases'. The epidemiological data for these 'cases' were scrutinized, and where other individual or individuals were infected with a different pathogen (confirmed, other than campylobacter), or where the onset of illness was greater than 7 days from that of the 'case', that 'case' was excluded. 'Controls' were those cases of $C$. jejuni infection who did not report other illness in either the home or the community. For the analysis of household illness, all cases who reported living alone were excluded from the analysis.

Demographic and clinical differences were assessed using Pearson's $\chi^{2}$ test and the Student's $t$ test. Initial comparisons were undertaken using single risk variable analyses. Mantel-Haenszel odds ratios (OR) were calculated for each explanatory variable. Logistic regression was then applied to obtain maximumlikelihood estimates of the effect of exposures on the outcome of interest whilst controlling for confounding. Variables with a $P<0 \cdot 1$ from the single risk variable analysis were included initially and the model was simplified using the likelihood ratio (LR) test. Potential interactions (between the main effects included in the initial logistic regression model and age, gender and season) were also examined using this method.

\section{RESULTS}

Linked data were available for 3489 cases of $C$. jejuni infection reported during the first year of the surveillance scheme. Cases ranged from less than 1 month to 94 years in age (mean 39) and the gender distribution was even. Diarrhoea (96\%), abdominal pain (86\%) and fever $(81 \%)$ were the most commonly reported symptoms, and over a quarter $(28 \%)$ of cases reported bloody diarrhoea. Cases amassed 37386 days of illness (range 0-701 days) and 358 cases (10\%) were admitted to hospital for at least 1400 days. 
Table 1. Risk exposures for illness in the home - single risk variable analysis (exposures with a $\mathrm{P}<0 \cdot 1$ are shown)

\begin{tabular}{|c|c|c|c|c|c|c|}
\hline \multirow[b]{2}{*}{ Exposure } & \multicolumn{2}{|c|}{ Percent exposed } & \multirow[b]{2}{*}{ OR* } & \multirow[b]{2}{*}{$P$} & \multicolumn{2}{|c|}{$95 \% \mathrm{CI} \dagger$} \\
\hline & ‘Cases' & 'Controls' & & & Lower & Upper \\
\hline Increasing 10 year age group & - & - & $0 \cdot 85$ & $<0.001$ & $0 \cdot 81$ & $0 \cdot 89$ \\
\hline Skilled manual workers & $3 \cdot 7$ & $6 \cdot 7$ & $0 \cdot 53$ & $0 \cdot 02$ & $0 \cdot 32$ & $0 \cdot 90$ \\
\hline Unemployed workers & $0 \cdot 5$ & $1 \cdot 8$ & $0 \cdot 25$ & $0 \cdot 04$ & $0 \cdot 06$ & $1 \cdot 04$ \\
\hline School children & $10 \cdot 4$ & $4 \cdot 9$ & $2 \cdot 28$ & $<0.001$ & $1 \cdot 59$ & $3 \cdot 28$ \\
\hline Pre-school children & $20 \cdot 0$ & $8 \cdot 0$ & $2 \cdot 86$ & $<0.001$ & $2 \cdot 16$ & $3 \cdot 79$ \\
\hline British ethnicity & $82 \cdot 5$ & $88 \cdot 6$ & $0 \cdot 61$ & $<0.001$ & $0 \cdot 45$ & $0 \cdot 82$ \\
\hline Asian ethnicity & $10 \cdot 5$ & $5 \cdot 6$ & 1.98 & $<0.001$ & $1 \cdot 36$ & $2 \cdot 89$ \\
\hline Travel abroad & $26 \cdot 6$ & $18 \cdot 5$ & $1 \cdot 59$ & $<0.001$ & $1 \cdot 26$ & $2 \cdot 00$ \\
\hline Baby food & $8 \cdot 9$ & $4 \cdot 2$ & $2 \cdot 26$ & $<0.001$ & $1 \cdot 48$ & $3 \cdot 44$ \\
\hline Barbecued food & $22 \cdot 1$ & $18 \cdot 4$ & $1 \cdot 26$ & $0 \cdot 08$ & $0 \cdot 97$ & $1 \cdot 62$ \\
\hline Beef (incl. roast, mince, steak) & $68 \cdot 6$ & $72 \cdot 5$ & $0 \cdot 82$ & 0.09 & $0 \cdot 83$ & $0 \cdot 10$ \\
\hline Cold meats (pre-cooked) & $63 \cdot 5$ & $73 \cdot 9$ & $0 \cdot 61$ & $<0.001$ & $0 \cdot 49$ & $0 \cdot 77$ \\
\hline Halal meats & $9 \cdot 4$ & $7 \cdot 0$ & $1 \cdot 39$ & 0.08 & $0 \cdot 96$ & $2 \cdot 00$ \\
\hline Organic meats & $6 \cdot 0$ & $3 \cdot 9$ & $1 \cdot 56$ & $0 \cdot 06$ & $0 \cdot 98$ & $2 \cdot 50$ \\
\hline Pork, ham or bacon & $74 \cdot 5$ & $80 \cdot 7$ & $0 \cdot 70$ & $0 \cdot 003$ & $0 \cdot 55$ & $0 \cdot 89$ \\
\hline Pre-packed sandwiches & $33 \cdot 8$ & $44 \cdot 4$ & $0 \cdot 64$ & $<0 \cdot 001$ & $0 \cdot 51$ & $0 \cdot 80$ \\
\hline Handling raw meat (increasing frequency) & - & - & $0 \cdot 83$ & $<0.001$ & $0 \cdot 76$ & $0 \cdot 91$ \\
\hline Unpasteurized milk & $10 \cdot 7$ & $7 \cdot 6$ & $1 \cdot 45$ & $0 \cdot 03$ & $1 \cdot 03$ & $2 \cdot 04$ \\
\hline Engineering work or supply problems (water) & $9 \cdot 7$ & $5 \cdot 0$ & $2 \cdot 07$ & $<0.001$ & $1 \cdot 43$ & $2 \cdot 98$ \\
\hline Swimming & $28 \cdot 6$ & $19 \cdot 2$ & $1 \cdot 69$ & $<0.001$ & $1 \cdot 35$ & $2 \cdot 12$ \\
\hline Sailing & $3 \cdot 88$ & $1 \cdot 66$ & $2 \cdot 39$ & $0 \cdot 002$ & $1 \cdot 34$ & $4 \cdot 28$ \\
\hline Contact with a pet horse & $2 \cdot 2$ & $1 \cdot 0$ & $2 \cdot 18$ & $0 \cdot 04$ & $1 \cdot 00$ & $4 \cdot 74$ \\
\hline Contact with a pet rodent & $7 \cdot 5$ & $4 \cdot 4$ & $1 \cdot 76$ & $0 \cdot 008$ & $1 \cdot 15$ & $2 \cdot 69$ \\
\hline Contact with a pet with diarrhoea & $11 \cdot 8$ & $6 \cdot 5$ & $1 \cdot 93$ & $0 \cdot 005$ & $1 \cdot 21$ & $3 \cdot 10$ \\
\hline Visiting a farm & $15 \cdot 9$ & $9 \cdot 6$ & $1 \cdot 79$ & $0 \cdot 001$ & $1 \cdot 25$ & $2 \cdot 55$ \\
\hline Increasing number of household members & - & - & $1 \cdot 08$ & $<0.001$ & $1 \cdot 03$ & $1 \cdot 13$ \\
\hline
\end{tabular}

* Odds ratio; $\dagger$ exact confidence interval.

\section{Other illness in the household}

Of the 3070 cases of $C$. jejuni infection who did not live alone, 509 cases $(17 \%)$ reported another individual or individuals within the household with similar symptoms at the same time (66 cases did not respond to the question). Of the 509 cases reporting other persons with similar illness, 41 cases reported that the other ill individual or individuals had a date of onset greater than 1 week from the case and three individuals were confirmed as being infected with another gastrointestinal pathogen. These cases were excluded, leaving 465 'cases' and 2495 'controls'.

Cases tended to be younger (mean age $30 \cdot 2$ years) than controls (mean age 37.5) $(t$ test, $P<0 \cdot 001)$ and were more likely to report vomiting ( 44.7 vs. $39.4 \%$; $P=0.04)$ and abdominal pain $(94.5$ vs. $92.0 \%$; $P=0 \cdot 04)$. There were no differences in gender $(51 \cdot 6$ vs. $50.5 \%$ male), length of illness ( 11.4 days each) or admission to hospital $(9 \cdot 5$ vs. $10 \cdot 5 \%)$.

\section{Exposures in the fortnight prior to illness} (Single risk variable analysis)

Cases were more likely to be school children or preschool children than controls and were more likely to be Asian (Table 1). They were more likely to have travelled outside the United Kingdom in the 2 weeks before illness and to report the consumption of certain foods, engineering work or problems with their water supply, or recreational exposure to water. They were more likely to have had contact with certain animals, or to have visited a farm in the 2 weeks prior to the onset of symptoms.

\section{Independent exposures in the fortnight prior to illness (logistic regression analysis)}

Cases were more likely to be pre-school or school children than controls (Table 2). They were more likely to have consumed organic meats in the winter, to have had contact with a pet suffering from 
Table 2. Independent risk exposures for illness in the home (logistic regression model controlling for age and gender)

\begin{tabular}{|c|c|c|c|c|}
\hline \multirow[b]{2}{*}{ Exposure } & \multirow[b]{2}{*}{$\mathrm{OR}^{*}$} & \multirow[b]{2}{*}{$P$} & \multicolumn{2}{|c|}{$95 \% \mathrm{CI} \dagger$} \\
\hline & & & Lower & Upper \\
\hline Organic meats in the winter & $6 \cdot 86$ & $0 \cdot 014$ & $1 \cdot 49$ & $31 \cdot 69$ \\
\hline School children & $2 \cdot 18$ & $0 \cdot 022$ & $1 \cdot 12$ & $4 \cdot 26$ \\
\hline Pre-school children & $2 \cdot 32$ & $0 \cdot 022$ & $1 \cdot 13$ & $4 \cdot 77$ \\
\hline Contact with pets with diarrhoea & $2 \cdot 19$ & $0 \cdot 005$ & $1 \cdot 27$ & $3 \cdot 77$ \\
\hline Visiting a farm & $2 \cdot 05$ & $0 \cdot 03$ & $1 \cdot 07$ & $3 \cdot 93$ \\
\hline Visiting a farm in summertime & $0 \cdot 24$ & $0 \cdot 03$ & $0 \cdot 07$ & $0 \cdot 87$ \\
\hline The winter & $0 \cdot 49$ & $0 \cdot 012$ & $0 \cdot 28$ & $0 \cdot 85$ \\
\hline Summertime & $1 \cdot 01$ & $0 \cdot 94$ & $0 \cdot 70$ & $1 \cdot 48$ \\
\hline Organic meats & $1 \cdot 14$ & $0 \cdot 76$ & $0 \cdot 49$ & $2 \cdot 68$ \\
\hline Age & 0.99 & $0 \cdot 229$ & $0 \cdot 98$ & $1 \cdot 01$ \\
\hline Gender & $1 \cdot 32$ & $0 \cdot 106$ & $0 \cdot 94$ & $1 \cdot 85$ \\
\hline
\end{tabular}

* Odds ratio; $\uparrow$ exact confidence interval.

diarrhoea or to have visited a farm in the 2 weeks before the onset of symptoms.

\section{Other illness in the community}

Of the 3489 cases of $C$. jejuni infection reported in the first year of the study, 333 (10\% reported knowledge of an individual outside the household with a similar illness. Of these, 10 cases (10/333) reported that the other ill individual or individuals had a date of onset greater than 1 week from the case. These cases were excluded, leaving 323 'cases' and 3048 'controls'.

Cases were, on average, younger (mean 32.5 years) than controls (mean 39 years) $(t$ test, $P<0 \cdot 001)$ and were more likely to be female $\left(56.7 v s .49 \cdot 5 \% ; \chi^{2} P=\right.$ $0 \cdot 01$ ). There was no difference between these groups of cases with regard to length of illness (mean 11 days each; $t$ test, $P=0 \cdot 9)$ or admission to hospital $(10 \cdot 8$ vs. $\left.10 \cdot 5 \% ; \chi^{2} P=0 \cdot 8\right)$.

Exposures in the fortnight prior to illness (single risk variable analysis)

Cases were more likely to be intermediate nonmanual workers (e.g. teachers, nurses, etc.) and farmers than controls (Table 3). They were more likely to be female and were more likely to have travelled outside or within the United Kingdom in the 2 weeks before illness. They were more likely to report the consumption of organic vegetables, vegetarian foods, food in restaurants, unpasteurized milk or bottled water. They were more likely to report swimming, sailing or contact with animals.
Independent exposures in the fortnight prior to illness (logistic regression analysis)

Cases tended to be younger than controls and were more likely to be intermediate non-manual workers (Table 4). They were more likely to report eating in restaurants and consuming unpasteurized milk.

\section{DISCUSSION}

Data from the first year of a large, population-based sentinel surveillance scheme suggests that point source outbreaks of $C$. jejuni infection in England and Wales, either in the home or in the community, might be more common than was previously thought. Casecase comparisons have allowed us to identify independent factors which might expose several individuals to campylobacter infection at the same time.

In the majority of instances, we were unable to determine the aetiological agent responsible for illness in other individuals reported to be symptomatic at the same time as the cases. This could have implications for the specificity of our case definition, since in some instances other illness reported by cases in the home or the community might not have been acquired from a common point source or might have been aetiologically unrelated. We examined extensively the available epidemiological data and excluded those cases where the illness might have been secondary or aetiologically unconnected in order to minimize false positivity. Conversely, some cases might have represented true clusters while not necessarily being aware of other related illness. However, our questionnaire 
Table 3. Risk exposures for illness in the community - single risk variable analysis (exposures with a $\mathrm{P}<0 \cdot 1$ are shown)

\begin{tabular}{|c|c|c|c|c|c|c|}
\hline \multirow[b]{2}{*}{ Exposure } & \multicolumn{2}{|c|}{ Percent exposed } & \multirow[b]{2}{*}{$\mathrm{OR}^{*}$} & \multirow[b]{2}{*}{$P$} & \multicolumn{2}{|c|}{$95 \% \mathrm{CI} \dagger$} \\
\hline & 'Cases’' & 'Controls' & & & Lower & Upper \\
\hline $\begin{array}{l}\text { South and West Devon } \\
\text { District Health Authority }\end{array}$ & $1 \cdot 2$ & $3 \cdot 3$ & $0 \cdot 36$ & $0 \cdot 04$ & $0 \cdot 13$ & $0 \cdot 99$ \\
\hline Increasing 10 -year age group & - & - & $0 \cdot 86$ & $<0.001$ & $0 \cdot 81$ & $0 \cdot 91$ \\
\hline Intermediate non-manual workers & $4 \cdot 6$ & $6 \cdot 3$ & $1 \cdot 76$ & $<0.001$ & $1 \cdot 30$ & $2 \cdot 37$ \\
\hline Farmers (employers and managers) & $0 \cdot 7$ & $0 \cdot 1$ & $9 \cdot 52$ & $0 \cdot 006$ & $1 \cdot 33$ & $68 \cdot 0$ \\
\hline Retired individuals & $8 \cdot 3$ & $18 \cdot 5$ & $0 \cdot 40$ & $<0.001$ & $0 \cdot 26$ & $0 \cdot 61$ \\
\hline Asian ethnicity & $2 \cdot 9$ & $6 \cdot 0$ & $0 \cdot 47$ & $0 \cdot 03$ & $0 \cdot 23$ & 0.96 \\
\hline Travel abroad & $23 \cdot 8$ & $18 \cdot 5$ & $1 \cdot 37$ & $0 \cdot 02$ & $1 \cdot 04$ & $1 \cdot 80$ \\
\hline Travel in the UK & $18 \cdot 6$ & $14 \cdot 2$ & $1 \cdot 38$ & $0 \cdot 04$ & $1 \cdot 01$ & $1 \cdot 88$ \\
\hline Barbecued food & $24 \cdot 6$ & $17 \cdot 5$ & $1 \cdot 53$ & $0 \cdot 004$ & $1 \cdot 15$ & $2 \cdot 04$ \\
\hline Lamb & $37 \cdot 1$ & $44 \cdot 3$ & $0 \cdot 74$ & $0 \cdot 02$ & $0 \cdot 58$ & 0.95 \\
\hline Meat pies & $19 \cdot 4$ & $29 \cdot 0$ & $0 \cdot 59$ & $<0.001$ & $0 \cdot 43$ & $0 \cdot 80$ \\
\hline Organic vegetables & $19 \cdot 1$ & $14 \cdot 9$ & $1 \cdot 34$ & 0.07 & $0 \cdot 97$ & $1 \cdot 85$ \\
\hline Vegetarian food & $24 \cdot 1$ & $19 \cdot 1$ & $1 \cdot 34$ & $0 \cdot 04$ & $1 \cdot 01$ & $1 \cdot 79$ \\
\hline Eating in restaurants & $65 \cdot 7$ & $53 \cdot 4$ & $1 \cdot 67$ & $<0.001$ & $1 \cdot 31$ & $2 \cdot 13$ \\
\hline Unpasteurized milk & $11 \cdot 6$ & $7 \cdot 8$ & $1 \cdot 55$ & $0 \cdot 02$ & $1 \cdot 06$ & $2 \cdot 27$ \\
\hline Bottled water & $62 \cdot 0$ & $52 \cdot 7$ & $1 \cdot 46$ & $0 \cdot 002$ & $1 \cdot 14$ & $1 \cdot 86$ \\
\hline Swimming & $27 \cdot 7$ & $18 \cdot 8$ & $1 \cdot 65$ & $<0.001$ & $1 \cdot 28$ & $2 \cdot 15$ \\
\hline Sailing & $3 \cdot 6$ & $1 \cdot 7$ & $2 \cdot 08$ & $0 \cdot 03$ & $1 \cdot 07$ & $4 \cdot 05$ \\
\hline Contact with animals & $64 \cdot 0$ & $57 \cdot 3$ & $1 \cdot 32$ & $0 \cdot 02$ & $1 \cdot 04$ & $1 \cdot 68$ \\
\hline Contact with pet rodents & $6 \cdot 6$ & $4 \cdot 1$ & $1 \cdot 63$ & $0 \cdot 06$ & $0 \cdot 97$ & $2 \cdot 73$ \\
\hline
\end{tabular}

* Odds ratio; $\uparrow$ exact confidence interval.

Table 4. Independent risk exposures for illness in the community (logistic regression model controlling for age, gender and season)

\begin{tabular}{|c|c|c|c|c|}
\hline \multirow[b]{2}{*}{ Exposure } & \multirow[b]{2}{*}{$\mathrm{OR}^{*}$} & \multirow[b]{2}{*}{$P$} & \multicolumn{2}{|c|}{$95 \% \mathrm{CI} \dagger$} \\
\hline & & & Lower & Upper \\
\hline $\begin{array}{l}\text { Farmers (employers and } \\
\text { managers) }\end{array}$ & $3 \cdot 89 \times 10^{9}$ & - & - & - \\
\hline Unpasteurized milk & $2 \cdot 15$ & $0 \cdot 002$ & $1 \cdot 33$ & $3 \cdot 49$ \\
\hline $\begin{array}{l}\text { Intermediate non-manual } \\
\text { workers }\end{array}$ & $1 \cdot 49$ & $0 \cdot 045$ & $1 \cdot 01$ & $2 \cdot 19$ \\
\hline Restaurants & $1 \cdot 40$ & 0.036 & $1 \cdot 02$ & $1 \cdot 92$ \\
\hline Asian ethnicity & $0 \cdot 28$ & $0 \cdot 01$ & $0 \cdot 11$ & $0 \cdot 74$ \\
\hline Meat pies & $0 \cdot 56$ & $0 \cdot 003$ & $0 \cdot 38$ & $0 \cdot 82$ \\
\hline Age group (increasing) & $0 \cdot 82$ & $<0.001$ & $0 \cdot 75$ & $0 \cdot 89$ \\
\hline Male gender & $0 \cdot 75$ & $0 \cdot 059$ & $0 \cdot 55$ & $1 \cdot 01$ \\
\hline Season & $0 \cdot 95$ & $0 \cdot 528$ & $0 \cdot 82$ & $1 \cdot 10$ \\
\hline
\end{tabular}

* Odds ratio; $\dagger$ exact confidence interval.

contained specific questions about other individuals with similar symptoms at the same time, and we would expect that most cases would be aware of other concurrent illness resulting from point source exposures, particularly among individuals in their own home.

\section{Other illness in the household}

Concurrent illness within the household setting might be less important than in the community in public health terms as the numbers affected will tend to be 
smaller. However, there are still issues with regard to treatment and prevention, and our data suggest that simultaneous $C$. jejuni infection occurs more frequently in the household setting than in the community.

An association between the consumption of organic meats in the winter and other illness in the household might relate to a higher prevalence of $C$. jejuni in organic meats. In a study of Campylobacter spp. in 160 broiler flocks in Denmark, $100 \%$ of organic broiler flocks were positive, compared with $37 \%$ of conventional broiler flocks and $49 \%$ of extensive indoor broiler flocks [17]. The prevalence of exposure to organic meats was low, and the increased risk in the winter might relate to greater consumption of meat dishes, such as roasts, at this time of year [18]. We did not ask about the type of organic meat consumed. However, an accurate assessment of the risks associated with organic meats is needed, especially as the production [19] and consumption [20] of organic produce has increased dramatically in the United Kingdom recently.

The associations between pre-school and school children and other illness within the household might indicate selection bias. Individuals in households often share meals and activities, therefore it is possible that several members may become infected by a single contamination event. However, whilst symptomatic adults might not present to general practitioners (GPs), it is more likely that symptomatic children would be taken to their GP [21].

Contact with pets with diarrhoea was suspected as a source of campylobacter infection in man before campylobacters were recognized as important human pathogens [22]. Campylobacters have been isolated from a variety of domestic animals [23-27] and contact with animals has been implicated in several epidemiological studies of campylobacter infection [28-32]. Pets are often regarded as members of the household, and close contact with them increases the likelihood of disease transmission [33]. Owners, and possibly more importantly the children of owners [30], need to be made aware that pets might be an important source of campylobacter and other enteric infections. This might best be achieved at the pet shop or veterinarian level.

The role of farm visits as a source of enteric disease has been highlighted by outbreaks and incidents of Vero cytotoxin-producing Escherichia coli (VTEC) O157 infection. Like VTEC O157 [34-36], campylobacters are shed intermittently by symptomatic [37] and asymptomatic [38] farm animals and the infective dose for humans is low [5, 39]. Poor hygiene following contact with the farm environment might therefore lead to infection. Recent guidelines for the control of infection with VTEC O157 provide specific information for farms open to the public [36], and this advice applies equally to avoidance of campylobacter infection.

\section{Other illness in the community}

The consumption of unpasteurized milk has been associated with outbreaks of campylobacter infection in England and Wales [40-45]. Its inclusion here is therefore unsurprising, but it might add weight to other observed associations. Raw milk for drinking remains on sale despite overwhelming scientific evidence [46-49] about the risks associated with its consumption. Those who drink it believe that the health benefits outweigh the risks, although these have not been demonstrated [50]. Under current UK legislation [51] raw milk for drinking should be free from pathogenic micro-organisms. Enforcement, through inspection and testing by food authorities, is done at a frequency considered necessary to ensure that the requirements of the regulations are complied with. If raw milk for drinking is to remain on sale (several attempts by the Government to ban its sale have been unsuccessful [52]) then this frequency needs to be increased.

The association between eating in restaurants and other illness in the community might relate to poor hygiene in the commercial catering environment. Outbreaks of campylobacter infection have been shown to be associated with commercial catering premises [3, 4] and epidemiological studies of sporadic disease have linked chicken prepared by or eaten in a commercial food establishment with infection [53-55]. Caterers need to be made aware that contamination of the hands and the environment with campylobacters can occur whilst preparing raw meat dishes $[56,57]$, and this contamination can be spread to readyto-eat foods. An assessment of the risks involved in each step of the food preparation process, based on the principles of Hazard Analysis and Critical Control Points and in line with UK food safety legislation [58], is recommended if infection associated with, and poor consumer confidence in [59], these premises is to be avoided.

Older cases of $C$. jejuni infection were less likely to report other illness in the community. This might 
be artefactual. The questionnaires for infants and younger children are answered by their parents who might be aware of other illness through playgroups, schools, etc.

The independent inverse associations identified in this study might point towards poor outbreak recognition rather than sources of sporadic infection. Laboratory reports underestimate the true incidence of infection by a factor of eight [2], therefore a large number of people must be infected from the same source for that source to be identified amongst laboratoryconfirmed cases.

Finally, a note should be made on the independence of subjects included in this analysis. Ideally, each true cluster of disease would be represented by a single case. It is possible that some cases were, in fact, part of the same clusters, and this could have led to an over-estimation of effects due to factors related with those clusters.

\section{CONCLUSION}

Concurrent illness in the home and/or the community occurred more frequently than might have been expected, based on previous publications. The results of these analyses are plausible in that they highlight exposures which would have affected more than one member of a family or a community at the same time. Prevention of campylobacter infection requires that better methods of outbreak detection are developed, which in turn should lead to a better understanding of risk factors.

\section{ACKNOWLEDGEMENTS}

The Campylobacter Sentinel Surveillance Scheme Steering Committee consists of Mr A. Charlett (Head, PHLS Statistics Unit), Dr J. M. Cowden (Scottish Centre for Infection \& Environmental Health), Mrs J. A. Frost, Mr I. A. Gillespie, Ms J. Millward (Birmingham City Council), Dr K. R. Neal (Department of Epidemiology \& Public Health, University of Nottingham), Dr S. J. O’Brien, Dr M. J. Painter (Manchester Health Authority), Professor Q. Syed (CDSC North West), and Dr D. Tompkins.

The Campylobacter Sentinel Surveillance Scheme Collaborators: public health, environmental health and laboratory staff who serve the populations of the following health authorities: Birmingham, Bradford, Bro Taf, Bury \& Rochdale, Dyfed Powys, East Kent,
Barnet, Enfield \& Haringey, Herefordshire, Leeds, Leicestershire, Manchester, North Cumbria, North Essex, North West Lancashire, Nottingham, Salford \& Trafford, South \& West Devon, South Lancashire, Southampton \& South West Hampshire, Stockport, West Pennine, Wigan \& Bolton. In association with: PHLS LEP, Campylobacter Reference Unit; PHLS CDSC, Gastrointestinal Diseases Division \& Regional Services Division; PHLS Statistics Unit.

This publication was written by: I. A. Gillespie, S. J. O'Brien, G. K. Adak, C. C. Tam (CDSC), J. A. Frost, F. J. Bolton (Central Public Health Laboratory) and D. S. Tompkins (Leeds Public Health Laboratory).

\section{REFERENCES}

1. Public Health Laboratory Service. Campylobacter spp. laboratory reports. England and Wales, faecal isolates, 1986-2000. www.phls.co.uk/facts/Gastro/Campy/campyAnn.htm (accessed 16/3/2001).

2. Wheeler JG, Sethi D, Cowden JM, et al. Study of infectious intestinal disease in England: rates in the community, presenting to general practice, and reported to national surveillance. BMJ 1999; 318: 1046-50.

3. Pebody RG, Ryan MJ, Wall PG. Outbreaks of campylobacter infection: rare events for a common pathogen. CDR Rev 1997; 7: R33-R37.

4. Frost FA, Gillespie IA, O'Brien SJ. Public health implications of campylobacter outbreaks in England and Wales, 1995-1999: epidemiological and microbiological investigations. Epidemiol Infect 2002; 128: 111-8.

5. Department of Health. Management of outbreaks of foodborne illness. London: Department of Health, 1994.

6. Rooney R, O'Brien SJ, Mitchell R, Stanwell-Smith R, Cook PE. Survey of local authority approaches to investigating sporadic cases of suspected food poisoning. Commun Dis Public Health 2000; 3: 101-5.

7. Committee on the Microbiological Safety of Food. The Microbiological Safety of Food, Part 1. London: HMSO, 1990.

8. CDSC. Sentinel surveillance of campylobacter in England and Wales. CDR 2000; 10: 169, 172.

9. CDSC. Campylobacter sentinel surveillance: the first year. CDR (Long Engl Wkly) 2001; 11 (35).

10. Fenton K, White J, Gillespie I, Morgan D, O'Brien S. Quarterly communicable disease review. July to September 2001. J Public Health Med 2002; 24: 63-9.

11. McCarthy N, Giesecke J. Case-case comparisons to study causation of common infectious diseases. Int $\mathbf{J}$ Epidemiol 1999; 28: 764-8.

12. Bolton FJ, Wareing DR, Skirrow MB, Hutchinson DN. Identification and biotyping of campylobacters. In: Board GR, Jones D, Skinner FA, eds. Identification methods in applied and environmental microbiology. Oxford: Blackwell Scientific Publications, 1992: 151-61. 
13. Frost JA, Oza AN, Thwaites RT, Rowe B. Serotyping scheme for Campylobacter jejuni and Campylobacter coli based on direct agglutination of heat-stable antigens. J Clin Microbiol 1998; 36: 335-9.

14. Frost JA, Kramer JM, Gillanders SA. Phage typing of Campylobacter jejuni and Campylobacter coli and its use as an adjunct to serotyping. Epidemiol Infect 1999; 123: 47-55.

15. Thwaites RT, Frost JA. Drug resistance in Campylobacter jejuni, C. coli, and C. lari isolated from humans in north west England and Wales, 1997. J Clin Pathol 1999; 52: 812-4.

16. Office of Population Censuses and Surveys. Standard Occupational Classification Volume 3: Social Classification and Coding Methodology. London: HMSO, 1991.

17. Heuer OE, Pedersen K, Andersen JS, Madsen M. Prevalence and antimicrobial susceptibility of thermophilic campylobacter in organic and conventional broiler flocks. Lett Appl Microbiol 2001; 33: 269-74.

18. Department for Environment F\&RA. National Food Survey 2000. London: HMSO, 2001.

19. Department for Environment F\&RA. Statistics on the organic sector. http://www.defra.gov.uk/farm/organic/ stat.htm (updated 10/8/2001; accessed 16/4/2002).

20. Anonymous. Organic food sales booming in UK. http:// news.bbc.co.uk/hi/english/business/newsid_1664000/ 1664253.stm (updated 19/11/2002; accessed 16/4/2002).

21. Department of Health. A report on the study of infectious intestinal disease in England. London: HMSO, 2000.

22. Wheeler WE, Borchers J. Vibrionic enteritis in infants. Am J Dis Child 1961; 101: 60-6.

23. Hastings DH. Campylobacter enteritis in pets. Lancet 1978; ii: $1249-50$.

24. Skirrow MB. Campylobacter enteritis: a 'new' disease. BMJ 1977; 2: 9-11.

25. Svedhem A, Kaijser B. Isolation of Campylobacter jejuni from domestic animals and pets: probable origin of human infection. J Infect 1981; 3: 37-40.

26. Moreno GS, Griffiths PL, Connerton IF, Park RW. Occurrence of campylobacters in small domestic and laboratory animals. J Appl Bacteriol 1993; 75: 49-54.

27. Hald B, Madsen M. Healthy puppies and kittens as carriers of Campylobacter spp., with special reference to Campylobacter upsaliensis. J Clin Microbiol 1997; 35: 3351-2.

28. Blaser M, Cravens J, Powers BW, Wang WL. Campylobacter enteritis associated with canine infection. Lancet 1978; ii: 979-81.

29. Norkrans G, Svedhem A. Epidemiological aspects of Campylobacter jejuni enteritis. J Hyg 1982; 89: 163-70.

30. Salfield NJ, Pugh EJ. Campylobacter enteritis in young children living in households with puppies. BMJ (Clin Res Ed) 1987; 294: 21-2.

31. Adak GK, Cowden JM, Nicholas S, Evans HS. The Public Health Laboratory Service national casecontrol study of primary indigenous sporadic cases of campylobacter infection. Epidemiol Infect 1995; 115: 15-22.
32. Tenkate TD, Stafford RJ. Risk factors for campylobacter infection in infants and young children: a matched case-control study. Epidemiol Infect 2001; 127: 399-404.

33. Fox JG, Moore R, Ackerman JI. Canine and feline campylobacteriosis: epizootiology and clinical and public health features. J Am Vet Med Assoc 1983;183: 1420-4.

34. Chapman PA, Siddons CA, Gerdan Malo AT, Harkin MA. A 1-year study of Escherichia coli O157 in cattle, sheep, pigs and poultry. Epidemiol Infect 1997; 119: 245-50.

35. Mechie SC, Chapman PA, Siddons CA. A fifteen month study of Escherichia coli O157:H7 in a dairy herd. Epidemiol Infect 1997; 118: 17-25.

36. Anonymous. Guidelines for the control of infection with Vero cytotoxin producing Escherichia coli (VTEC). Subcommittee of the PHLS Advisory Committee on Gastrointestinal Infections. Commun Dis Public Health 2000; 3: 14-23.

37. Prescott JF, Bruin-Mosch CW. Carriage of Campylobacter jejuni in healthy and diarrheic animals. Am J Vet Res $1981 ; 42$ : 164-5.

38. Wesley IV, Wells SJ, Harmon KM, et al. Fecal shedding of Campylobacter and Arcobacter spp. in dairy cattle. Appl Environ Microbiol 2000; 66: 1994-2000.

39. Black RE, Levine MM, Clements ML, Hughes TP, Blaser MJ. Experimental Campylobacter jejuni infection in humans. J Infect Dis 1988; 157: 472-9.

40. Galbraith NS, Forbes P, Clifford C. Communicable disease associated with milk and dairy products in England and Wales 1951-80. BMJ (Clin Res Ed) 1982; 284: 1761-5.

41. Communicable Disease Surveillance Centre. Disease associated with milk and dairy products: 1982. BMJ (Clin Res Ed) 1984; 288: 466-7.

42. Anonymous. Disease associated with milk and dairy products: 1982 . BMJ 1984; 288: 466-7.

43. Anonymous. Communicable disease associated with milk and dairy products England and Wales 1985-86. CDR 1987; 87: 3-4.

44. Barrett NJ. Communicable disease associated with milk and dairy products in England and Wales: 1983-1984. J Infect 1986; 12: 265-72.

45. Sockett PN. Communicable disease associated with milk and dairy products: England and Wales 1987-1989. CDR 1991; 1: R9-12.

46. Advisory Committee on the Microbiological Safety of Food. Report on verocytoxin-producing Escherichia coli. London: HMSO, 1995.

47. Department of Health. Surveillance of the microbiological status of raw cows' milk on retail sale. London: Department of Health, 1998.

48. de Louvois J, Rampling A. One fifth of samples of unpasteurised milk are contaminated with bacteria. BMJ 1998; 316 : 625.

49. Anonymous. Task Force on E. coli O157. Final report. 2001.

50. Potter ME, Kaufmann AF, Blake PA, Feldman RA. Unpasteurized milk. The hazards of a health fetish. JAMA 1984; 252 : 2048-52. 
51. Ministry of Agriculture Fisheries and Food. Department of Health. Welsh Office. The Dairy Products (Hygiene) Regulations 1995. London: HMSO, 1995.

52. Food Standards Agency. Sale of unpasteurised drinking milk and cream. http://www.food.gov.uk/foodindustry/ Consultations/consultwales/rawmilkcream (updated 24/1/2002; accessed 5/3/2002).

53. Eberhart-Phillips J, Walker N, Garrett N, et al. Campylobacteriosis in New Zealand: results of a casecontrol study. J Epidemiol Community Health 1997; 51: 686-91.

54. Effler P, Ieong MC, Kimura A, et al. Sporadic Campylobacter jejuni infections in Hawaii: associations with prior antibiotic use and commercially prepared chicken. J Infect Dis 2001 ; 183: 1152-5.

55. Rodrigues LC, Cowden JM, Wheeler JG, et al. The study of infectious intestinal disease in England: risk factors for cases of infectious intestinal disease with Campylobacter jejuni infection. Epidemiol Infect 2001; 127: 185-93.

56. De Boer EE, Hahné M. Cross-contamination with Campylobacter jejuni and Salmonella spp. from raw chicken products during food preparation. J Food Prot 1990; 53: 1067-8.

57. Dawkins HC, Bolton FJ, Hutchinson DN. A study of the spread of Campylobacter jejuni in four large kitchens. J Hyg 1984; 92: 357-64.

58. Ministry of Agriculture Fisheries and Food. Department of Health. Scottish Office. Welsh Office. Food Safety (General Food Hygiene) Regulations 1995. London: HMSO, 1995.

59. Food Standards Agency. Consumer attitudes to food standards. 11/2/2002. London, Taylor Nelson Sofres Consumer. 